\title{
Teaching Mathematics to Electrical Engineering Students by Electrical Engineering Staff in College of Technology in Japan
}

\author{
http://dx.doi.org/10.3991/ijep.v3iS4.3217 \\ Akira Fujimoto, Masatoshi Tokuda, Toru Mori and Toshiyuki Sakuma \\ Wakayama National College of Technology, Gobo, Wakayama, Japan
}

\begin{abstract}
Electrical engineering staff (reorganized to Electrical and Computer engineering in 2004) has taught electrical engineering students for mathematics classes in Wakayama National College of Technology (WNCT) in Japan from 2007. Effects of the mathematics classes by the electrical engineering staff were evaluated by using the results of the mathematics placement tests. The results of the tests are compared with averages of other National Colleges of Technology in Japan and other divisions of WNCT. As a result, an ability of electrical engineering students for mathematics improved dramatically with increasing the ratio of mathematics classes by the electrical engineering staff. It should seem that these good results were achieved by eagerness and strong motivation of the staff with electrical specialty for improving the ability of their division's students. The reasons for the improvement are discussed and the unique class of mathematics for college of technology is also introduced.
\end{abstract}

Index Terms - engineering education, mathematics class.

\section{INTRODUCTION}

The National College of Technology in Japan (Kosen) was established to educate practical engineer. The college has the following features, (1) engineering education for an early age, (2) 5 year consistent system for engineering education; (3) almost all graduates become an engineer in the future. The education of the college can be specialized to engineering education because the future of graduates is well defined to engineer.

The mission of the staff of the college should be training students to master knowledge and ability for engineer within just 5 years. The staff of the Kosen has to select the subjects to teach them and to do the class effectively. The students of electrical engineering department also have to master with highly level the basic abilities for electrical engineer in future.

The electrical related subjects are easy to show the relation to the practical work after graduation and to be interest in the students; however, the general education subjects for the lower class are difficult to show the relation. The students must master the mathematics, one of the general education subjects, during the lower class, because the mathematics is the basic and important of all the electrical engineering subjects ${ }^{1)}$. The electrical engineering department staff has been examined for the students being interest in the mathematics which need the electromagnetic and electrical circuits' related subjects ${ }^{2}$.

TABLE I.

TMATTERS OF MATHEMATICS FOR LEARNING ELECTRICAL CIRCUITS.

\begin{tabular}{|c|c|c|}
\hline M athem atics & Contents of Electric C ircu it & T arget of Understanding in $\mathrm{M}$ athem atics \\
\hline \multicolumn{3}{|l|}{ First Year } \\
\hline $\begin{array}{l}\text { How to solve simultaneous equations } \\
\text { C ram m er's Rule) }\end{array}$ & $\begin{array}{l}\text { DC C ircu it QC Pow er Souce and } \\
\text { Equ ivalent C ircu it, } 0 \text { hm 's Law, Series \& } \\
\text { Paralle I C onnection of Resistance, } \\
\text { Series \& Paralle I C ircu it, Y- } \Delta \\
\text { convers ion, K irchhoff's Law, } \\
\text { Application of K irchhoff's Law ), } \\
\text { Theorem s of D C C ircu it, Application of } \\
\text { Theven n's theorem }\end{array}$ & $\begin{array}{l}\text { (1) How to so ve sim ultaneous equations Q ing } \\
\text { K irchhoff's Law--up to } 3 \text { Variables) } \\
\text { (2) In } C \text { ase of } Y-\Delta \text { conversion, It's poss ble to } \\
\text { so Ne sim u ltaneous equations. } \\
\text { (3) C ram m er's Rule }\end{array}$ \\
\hline \multicolumn{3}{|l|}{ Second Year } \\
\hline \begin{tabular}{|l|} 
Trigonom etrical Function, \\
Vector,C om plex N um ber, (D ifferential \\
C a lcu us. Integral C alcu us)
\end{tabular} & $\begin{array}{l}\text { S nuso idal AC wave Rhasor Equ ivalent } \\
\text { of S nuso idal wave, Property of C ircu it } \\
\text { E lem ents \& Phasor Equ Nalent, } \\
\text { Com plex N um ber C onvers ion of } \\
\text { S nuso idal w ave, para ll I C onnection, } \\
\text { m pedance \& Adm ittance C onnection), } \\
\text { Tw o-te m nal N etw ork ( Series } \\
\text { Connection of m pedance,Series } \\
\text { Connection of m pedance \& } \\
\text { Adm ittance, Parall I C onection of } \\
\text { m pedance \& Adm ittance ) }\end{array}$ & 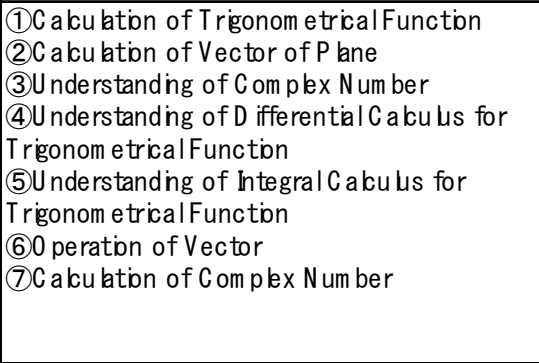 \\
\hline
\end{tabular}


TABLE II.

RELATIONS BETWEEN MATHEMATICAL AND SPECIFIC SUBJECTS.

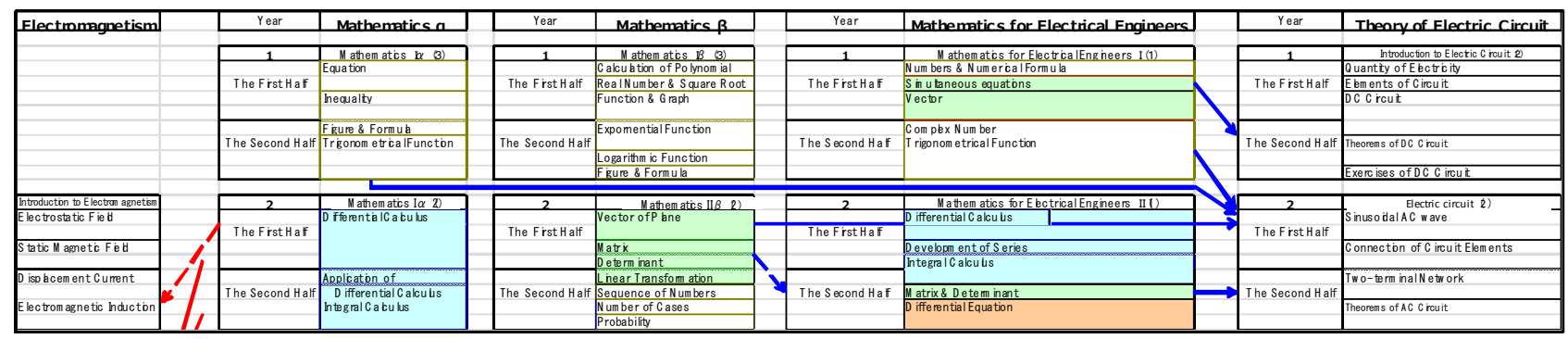

TABLE III.

MOVEMENTS OF THE MATHEMATICS RELATED SUBJECTS.

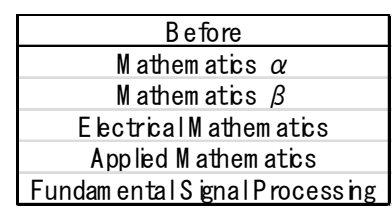

The electrical and computer engineering staff began to teach the mathematics class instead of the general education staff to their student from 2004 together with selection of important matters of mathematics. The ratio of the giving mathematics class by electrical and computer engineering staff increased gradually and all mathematics class were given by the staff from 2007 . The examination was done by 41 staff of 28 colleges of technology in one year under special supports by Institute of National College of Technology, Japan in $2006^{3)}$. In this paper, the examination process and the results from the student's ability are introduced.

\section{EXAMINATION TO IMPROVE MATHEMATICS CLASS}

To improve the mathematics class of electrical engineering department, working team which consist of general education staff and electrical and computer engineering staff was set up at 2002. The matters which need to learn subjects related to electrical engineering and the aim of study of the mathematics for electrical engineering. First, the mathematics matters which are needed to learn basic subjects such as electromagnetism, electrical circuits and information were listed and arranged. The arrangement results for electrical circuit are shown in Table 1. Second, learning times of the major subjects were compared with the matters of the mathematics. If the times which learn major subject and learn the related matters of mathematics match well, the students can apply the matters of mathematics to the major

TABLE IV

Ratio of electrical and computer engineering staff who were teaching mathematics.

\begin{tabular}{|c|c|c|c|c|c|c|}
\hline \multirow{3}{*}{$\begin{array}{c}\text { Academ ic } \\
\text { year }\end{array}$} & \multirow{2}{*}{\multicolumn{2}{|c|}{$\begin{array}{c}\text { First-year student } \\
\text { Fundam entalm athem atics }\end{array}$}} & \multirow{2}{*}{\multicolumn{2}{|c|}{\begin{tabular}{c|} 
Second-year student \\
M athem atics
\end{tabular}}} & \multirow{2}{*}{\multicolumn{2}{|c|}{$\begin{array}{c}\text { Third-year student } \\
\text { M athem atics }\end{array}$}} \\
\hline & & & & & & \\
\hline & General $^{k 1}$ & Specia ${ }^{k^{2}}$ & Genera $^{* 1}$ & Specia $\left.\right|^{* 2}$ & General $^{k+1}$ & Special ${ }^{2}$ \\
\hline 2003 & $100 \%$ & $0 \%$ & $100 \%$ & $0 \%$ & $100 \%$ & $0 \%$ \\
\hline 2004 & $67 \%$ & $33 \%$ & $100 \%$ & $0 \%$ & $100 \%$ & $0 \%$ \\
\hline 2005 & $67 \%$ & $33 \%$ & $67 \%$ & $33 \%$ & $100 \%$ & $0 \%$ \\
\hline 2006 & $67 \%$ & $33 \%$ & $67 \%$ & $33 \%$ & $67 \%$ & $33 \%$ \\
\hline 2007 & $0 \%$ & $100 \%$ & $0 \%$ & $100 \%$ & $0 \%$ & $100 \%$ \\
\hline 2008 & $0 \%$ & $100 \%$ & $0 \%$ & $100 \%$ & $0 \%$ & $100 \%$ \\
\hline 2009 & $0 \%$ & $100 \%$ & $0 \%$ & $100 \%$ & $0 \%$ & $100 \%$ \\
\hline 2010 & $0 \%$ & $100 \%$ & $0 \%$ & $100 \%$ & $0 \%$ & $100 \%$ \\
\hline 2011 & $0 \%$ & $100 \%$ & $0 \%$ & $100 \%$ & $0 \%$ & $100 \%$ \\
\hline
\end{tabular}

subjects and can master the matters well. Table 2 shows an example of the times of learning the major subjects and the related matters of mathematics.

\section{IMPROVEMENT METHOD AND PRACTICE}

The mathematics of WNCT divided five subjects as follows; "Mathematics A", "Mathematics B", "Electrical Mathematics", "Applied Mathematics" and "Basic Signal Processing". These subjects were arranged following three subjects by examination of working team; required subject of "Basic Mathematics" which includes the matters for all department graduates of KOSEN, required subject of "Special Mathematics" which relates the electrical engineering subjects, and optional subject of "Special Mathematics", for the students who go to the university. "Basic Signal Processing" and "Applied Mathematics" moved to "Probability and Statistics" and "Applied Mathematics" with highly specialized. These movements are shown in Table 3. The results were well examined with members under special supports by Institute of National College of Technology mentioned above ${ }^{4}$.

Many students who entered to the decided department of the KOSEN were interest in their specialties. This situation suggests that teaching the mathematics together with the matter of specialty subjects leads to deep comprehensive of the mathematical matters. We think that showing to students the mathematics is not dependent subject and the mathematics strongly relates to the specialty subjects lead to realize the effective class of the mathematics.

Electrical and computer engineering staff have begun to teach partially and increased year by year the ratio of electrical and computer engineering staff who were teaching mathematics as shown in Table 4. It was expected that the electrical and computer engineering staff thought the mathematics naturally together with related matters of specific subjects.

In the case of calculation for volume of body of rotation, they use an example of the Torpedo Car which carries pig iron in ironworks shown in figure 1 to make easy understanding the calculation. 


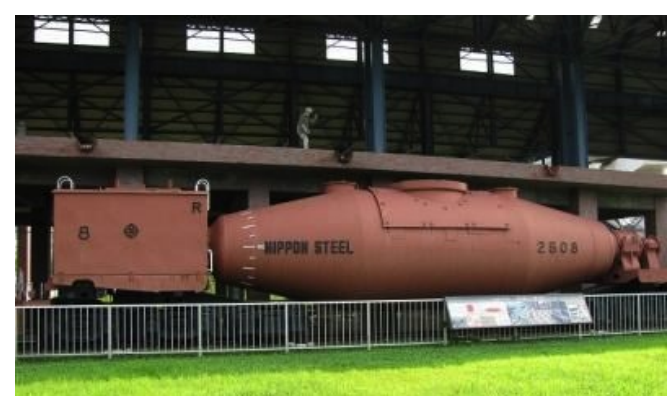

(a)

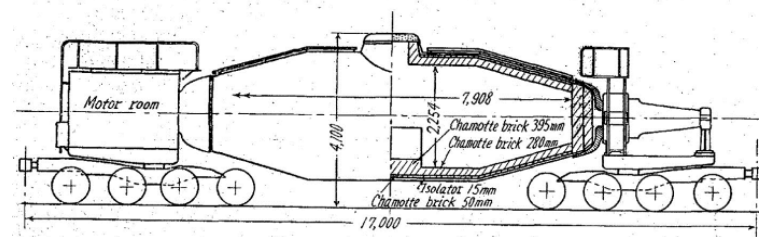

(b)

Figure 1. Photo (a) and cross section (b) of Torpedo Car.

When a vacancy occurred at mathematics teacher, the man whose specialty was electrical engineering was employed as a mathematics teacher for electrical and computer engineering department along with the above policy.

\section{RESULTS AND DISCUSSIONS}

The mathematics and physics placement tests of the Institute of National College of Technology Japan which introduced from 2006 for $3^{\text {rd }}$ grade students of KOSEN were uses for evaluation of the above actions.

\section{A. Mathematics}

The marks of the students of electrical and computer engineering department for the mathematics placement tests at eight contents were compared with the average mark of all KOSEN students and all electrical and all information departments of KOSEN. The relation between the compared results and the ratio of electrical and computer engineering staff who were teaching mathematics are shown in figure 1. The first year of placement tests in 2006, the average of the mathematics

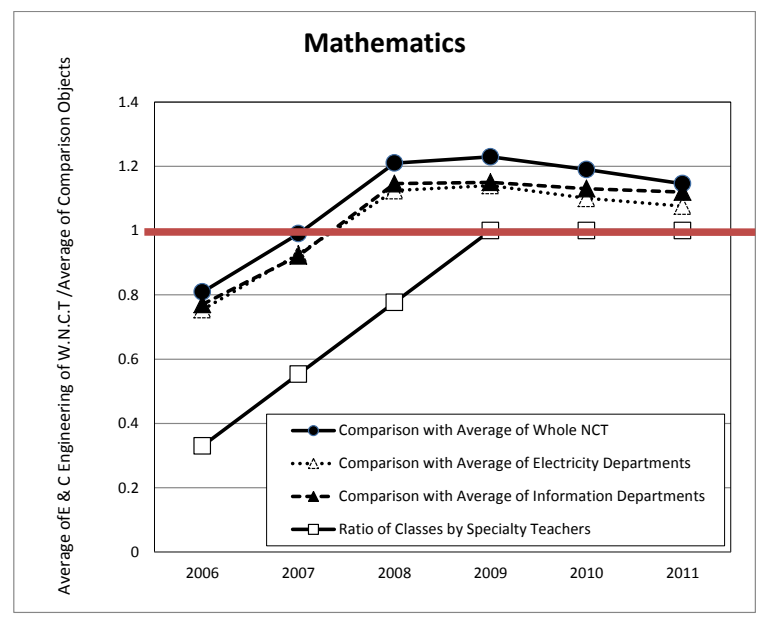

Figure 2. Change of average marks of mathematics with electrical and computer engineering staff teaching mathematics.

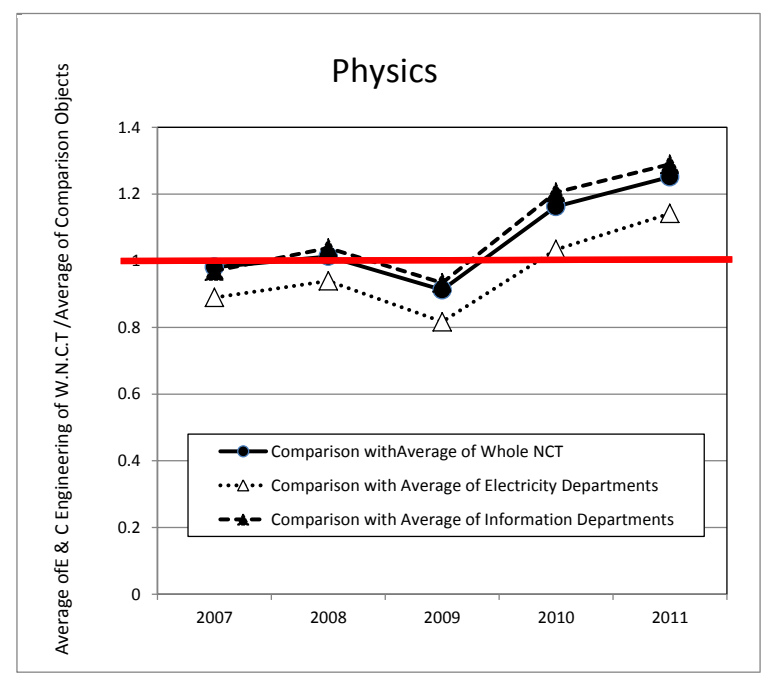

Figure 3. Changes of the average marks of the mathematics placement test for WNCT students and all KOSEN students.

mark of electrical and computer engineering department's students of WNCT was lower of $20 \%$ than the average mark of all KOSEN students and all electrical and all information departments of KOSEN. The mark of students of WNCT increased with increasing the ratio of teaching mathematics staff of electrical and computer engineering department and the average mark of WNCT students beyond the average of the mark of all KOSEN of $20 \%$ in 2008 when the ratio reached to $80 \%$. The advantage of the average of the mark was kept till now.

\section{B. Physics}

Figure 3 shows the mark of physics placement test which started one year after the mathematics test. The mark of physics did not increase as the mathematics at the beginning, however, the mark increased gradually similar to figure 2 since 2010 with spreading the class which thought the physics with the matter of specific subjects from the first year of students. The mark of physics of WNCT students increased to above $20 \%$ of average of all KOSEN since 2010, although the mark was lower than the average or equal to the average before that time.

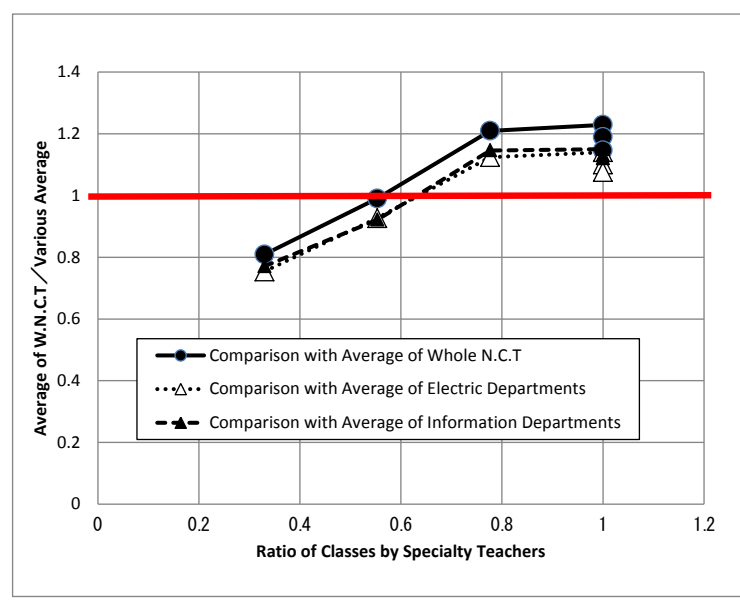

Figure 4. Ratio dependence of the mathematics teaching specific staff on the marks of the mathematics placement test for the electrical and computer engineering students. 


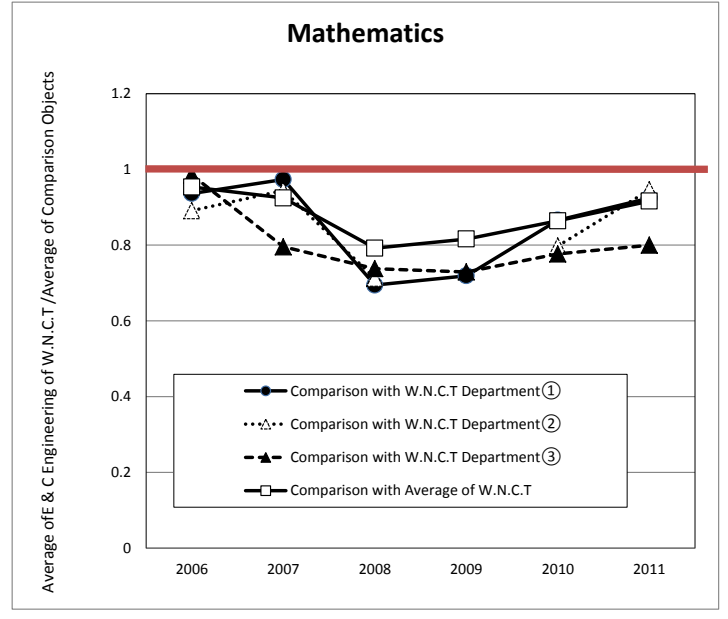

Figure 5. Change of average marks of mathematics for other departments students of WNCT.

\section{Ratio dependence of the mathematics teaching specific staff on the mathematics placement tests marks}

Figure 4 shows that the ratio dependence of the mathematics teaching specific staff during the first to third grade on the mathematics placement tests marks of the electrical and computer engineering students. The vertical axis shows the ratios of the average mark of electrical and computer engineering department of WNCT to the average marks of the all KOSEN, all electrical departments of KOSEN and all information departments of KOSEN. It is clear that the mathematics average mark of WNCT increases with increasing the ratio of the specific staff with teaching mathematics and there is strong correlation.

\section{D. Comparing the marks with other departments of WNCT}

\section{(1) Mathematics}

The average mark of mathematics of the electrical and computer engineering student was almost same or had advantage of $10 \%$ to the other departments of WNCT when the beginning of the placement test in 2006. The mathematics average mark of the electrical and computer engineering students reached 10-30\% higher than the

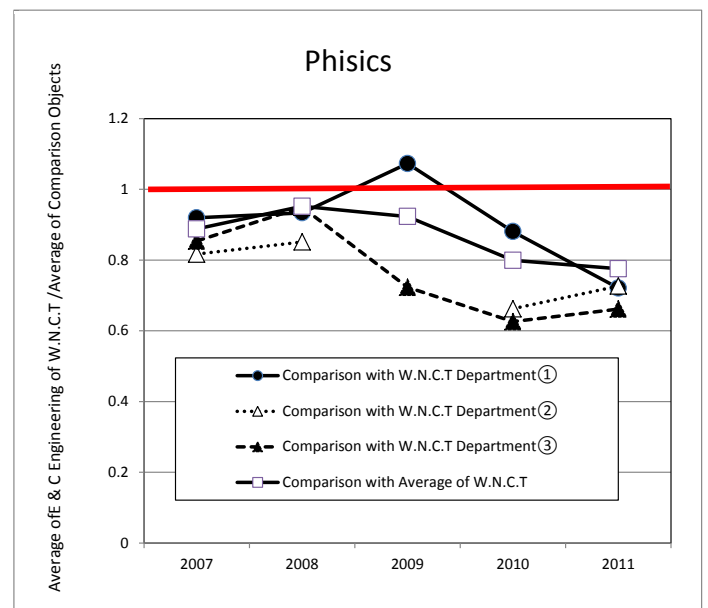

Figure 6. Change of average marks of physics for other departments students of WNCT.

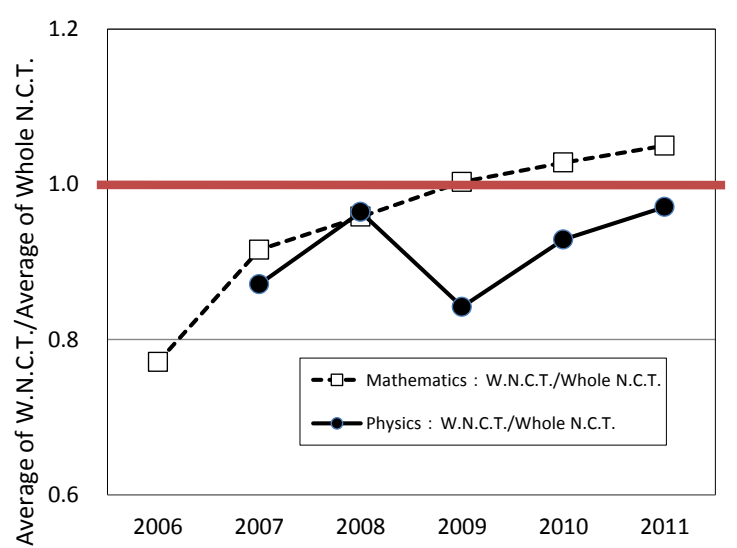

Figure 7. Changes of the marks of mathematics and physics of WNCT students versus average of all KOSEN students.

other departments students of WNCT after the ratio of the electrical and computer engineering staff teaching the mathematics reached to $80 \%$ in 2008. The general education staff whose specialty was mathematics thought the mathematics classes at the other departments of WNCT as before.

\section{(2) Physics}

The results of physics placement test which began after one year from the mathematics rest are shown in figure 6 . Although the advantage of the electrical and computer engineering department student to the other departments students was around 10-20\% when the physics placement test stated, the advantage increased to $20-40 \%$ after 2010 , spreading the thought and methods of new mathematics class described above.

\section{(3) Effects to other department of WNCT}

Although the average marks of the mathematics placement test of all students of WNCT were more $20 \%$ lower than the average mark of all students of KOSEN in 2006 when the placement test was introduced, the average marks of the test of WNCT students exceeded the average marks of all students of KOSEN after 2009 as shown in figure 7 . We suppose that one of the reasons is the improvement of the marks of electrical and computer engineering department's students act as a stimulus to the other three department's students. The reason is presumed from the average marks of the other department's students

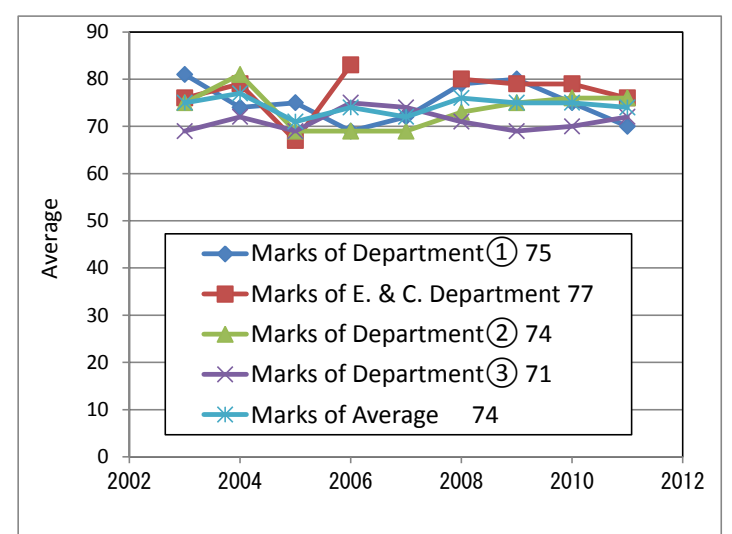

Fig.8 Marks of entrance examination of mathematics for students of each department of WNCT. 
is closing to the average mark of the electrical and computer engineering department's students shown in figure 5. On the other hand, the average mark of all students of WNCT was lower than the average mark of all students of KOSEN in physics. Though the average mark of WNCT students was about $85 \%$ of the average mark of all KOSEN at the beginning of placement test of 2006, the average mark of WNCT students increased $97 \%$ of average mark of all KOSEN students in 2011.

(3) The marks of entrance examination of mathematics of the students in each department of WNCT

An achievement test has been done every April for all new face of WNCT with same questions. The questions are selected from the matter of mathematics which treated in junior high school. No questions are known to next new face because the questions didn't back to students. The results of the test at recent nine years are shown in figure 8 . The average marks of the students of electrical and computer engineering department are almost same of the students of the other departmeünts. The fact suggests that the levels of the students in each department are same at the entrance and the marks of placement test at 3rd grade reflects the results of the education of mathematics after entrance the WNCT.

\section{E. Consideration}

The reasons of improvement to comprehension for the students are supposed as follows; a: electrical and computer engineering staff modulated the matter of mathematics which one was important and/or which one was unimportant in real industries, b: the staff could teach the matters of mathematics in relation to the matters of specific subjects, c: the staff motivated the students successfully by introducing how the matters of mathematics were used in real industries based on their experiences ${ }^{5}$.

In addition, the staff thought the students with warm enthusiasm because the students belonged to the staff' department. If the students didn't understand the matters of mathematics, the students might not understand the matters of the specific subjects which were the subjects of the staff. Such sense of crisis of the staff leaded to the warm enthusiasm and improvement of the comprehension.

\section{F. CONCLUSIONS}

The examination of mathematics class and the results of electrical and computer engineering staff thought the mathematics class are introduced. The marks of mathematics placement test show that there is strong correlation between the average mark of placement test and the ratio of the giving mathematics class by electrical and computer engineering staff and it is effective to improve the mathematics class to teach the mathematics by electrical and computer engineering staff.
We suppose that the reasons of the improvements are to teach the matters of mathematics together with the matters of specific subject based on their own experiences and to teach with warm enthusiasm by conscious that they are own students. Although some people think that the general mathematics staff has to teach the mathematics class for the students of high school age, the results of this trial show that teaching the mathematics by the electrical and computer engineering staff is effective to improve the class.

If the general education staff whose specialty is mathematics had the conscious that the students are their own students even the students belong to the special department, it is possible to realize the better mathematics class by their good education and specialty of the mathematics. The effective class will realize for high grade students who want to enter the university by their skillful specialty and their experiences.

\section{REFERENCES}

[1] for instance Babu Ram,"Engineering Mathematics", Pearson, 2010, p.xi.

[2] A. Fujimoto and K. Takagi, ".Setting upon the curriculum which utilized the feature of the National College of technology in Japan, referring to the mathematics of faculty of electrical engineering",2004 Kosen kyoiku ronbunshu, pp195-199, Aug. 2004 (in Japanese).

[3] "General education curriculumwhich can be realized by just Kosen, Setting upon theeducation programs which utilized the feature of the Kosen in Japan", The report of Tokubetsu Kyoiku Kenkyukeihi jigyo, edited by Wakayama National College of Technology, 2007 (in Japanese).

[4] M. Tokuda and A. Fujimoto, "Class of mathematics at department of electrical engineering by electrical engineering teacher", Report of Kansai devision of Japanese society for engineering education, No. 69, pp.10-11, March 2012 (in Japanese).

[5] A. Fujimoto, "Series learning from Kosen education, feature education and research of Wakayama Kosen No.5-Training engineers by practical using the degree of freedom of Kosen", Monbu-Kagaku kyoiku Tsushin, No.297, pp30-31, 2012 (in Japanese).

\section{AUTHORS}

A. Fujimoto is with the Electrical and Computer Engineering Department of Wakayama National College of Technology, 77 Noshima, Nadacho, Gobo-shi 6440023 JAPAN (e-mail: author@wakayama-nct.ac.jp).

M. Tokuda, T. Mori and T. Sakuma are the same to Fujimoto.

This article is an extended and modified version of a paper presented at the 2013 IEEE International Conference on Teaching, Assessment and Learning for Engineering (TALE2013), held 26-29 August 2013, Bali Dynasty Resort, Kuta, Indonesia. Submitted 30 September 2013. Published as re-submitted by the authors 01 December 2013. 